\title{
Effects of tagcloud-anchored group discussions on pre-service teachers' collaborative knowledge construction
}

\author{
Shu-Yuan Lin \\ Idaho State University \\ Ying Xie \\ Northern Illinois University
}

\begin{abstract}
Group discussions are critical for students constructing new understanding and knowledge in both classroom and distance education. Tagclouds can provide an intuitive overview about the group's collective knowledge and could potentially be used as an anchor for group discussions. The effect of using tagclouds as anchors for group discussions was examined. Thirty-two pre-service teachers were randomly assigned into six groups, and they blogged for five weeks. At the end of the blogging activity, three groups were randomly selected to participate in tagcloud-anchored discussions. Evidence of knowledge construction was collected from participants' concept maps, individual blog tags and group tagclouds. The result indicates tagcloud-anchored group discussions facilitated and enhanced the quality of knowledge construction as exhibited in their concept maps.
\end{abstract}

\section{Introduction}

Students' knowledge construction can take place through social interactions in collaborative environments. Vygotsky (1962) argued that a learner's cognitive growth is enhanced through guidance while interacting with capable peers or teachers. A significant aspect of sociocultural theories of learning emphasises the use of tools in mediating collaborative knowledge construction (Cole, 1996; Pea, 1993). Group discussions can serve as mediating tools for building knowledge. Research has indicated properly guided group discussions generally allow for different perspectives, encourage negotiations of meanings and therefore facilitate collaborative knowledge construction in both face-to-face and online learning contexts (Brookfield \& Preskill, 2005; Hale \& City, 2006).

Tagclouds, an add-on tool in weblogs (in this study), are visual presentations of words tagged to blogs. The attributes of the text are used to represent important features of the associated terms (Rivadeneira, Gruen, Muller, \& Millen, 2007; Sinclair \& Cardew-Hall, 2008). Similar to a table of contents, a tagcloud provides learners a general impression, supports tasks such as search and browsing (Rivadeneira et al., 2007) and generally represents well the group cognition of a team (Xie \& Lin, 2016). Despite the increasing use of tagclouds in educational settings, research is limited regarding the use of tagclouds to guide group discussions. The purpose of this study was to investigate the effect of using tagclouds as anchors to support pre-service teachers' knowledge construction in small groups. Specifically, this study sought to examine whether preservice teachers' participation in tagcloud-anchored discussions resulted in a significant difference in knowledge construction outcome as exhibited in their concept maps.

\section{Theoretical perspectives}

\section{Knowledge construction and group discussions}

Knowledge construction that takes place through social interactions is usually mediated by various tools used in a collaborative environment (Vygotsky, 1962). While recognising that knowledge is socially constructed, Pea (1993) emphasised collaborative efforts towards shared goals and contributions from individuals in the process of knowledge construction, for example, through dialogues. Schellens and Valcke (2005) reviewed models and theories regarding the process of building and sharing knowledge in a social-constructivist learning 
environment, including computer-supported collaborative learning (CSCL) settings. In this synthesised model, knowledge construction occurs at both the individual and social level in five phases:

(1) sharing/comparing, including observation, agreement, corroboration, clarification, and definition;

(2) dissonance/inconsistency: including identifying and stating, asking and clarifying, restating and supporting;

(3) negotiating what is to be agreed upon (and where conflicts exist)/co-construction: including proposing new co-constructions that encompass the negotiated resolution of the differences;

(4) testing tentative constructions: including the new constructed statements of ideas that may then be tested, and matched again to personal understandings and other resources (such as the literature);

(5) statement/application of newly constructed knowledge: including final revision and sharing again of the new ideas that have been constructed by the group. (Schellens \& Valcke, 2005, p. 960)

Group discussions have been widely acknowledged as valuable collaborative learning tools for students to actively exchange information and possibly construct knowledge with their peers and instructors (Brookfield \& Preskill, 2005; Hale \& City, 2006). Specifically, research studies found small-group discussions beneficial for student learning, including producing higher-quality of communication and participation (Lowry, Roberts, Romano, Cheney, \& Hightower, 2006), promoting meaningful discussions on task related facts, concept, and thinking (Meloth \& Deering, 1999) and enhancing students' learning and promoting their analytical and critical thinking skills (Gillies, 2011; Rabow, Charness, Kipperman, \& Radcliffe-Vasile, 1994).

Most previous studies of group discussions primarily focused on online discussion (see Dabbagh \& Kitsantas, 2005; Ng, Cheung, \& Hew, 2010; Yeh, Lo, \& Huang, 2011) or examined types of tools for online discussions (see Lim, 2010; Ng, Cheung, \& Hew, 2010). The tools were usually collaborative communication tools, including discussion forum, desktop videoconference, Internet Relay Chat and other chat tools. For example, Lim (2010) studied the effect of using chat tutorials to guide synchronous online discussions. In addition, a few studies also examined the use of technology tools to support face-to-face group discussions (see Chung, Lee, \& Liu, 2013; Nussbaum et al., 2009). To extend these two studies, this current study examined the effect of tagcloud-anchored group discussions.

\section{Use of tagclouds as anchors for small group discussions}

The popular Web 2.0 technologies offer new ways for students' knowledge co-construction through social negotiations in both classrooms and distance education (Reiser \& Dempsey, 2012). Social tagging yields a product, namely a tagcloud, which could be used to encourage student-student interactions.

Social tagging is the activity of annotating digital resources with keywords (Trant, 2009). Any individual in a community can link a keyword to some digital resource such as web pages, blogs and pictures to reflect specific meaning or relevance of the resource to the individual. When all tags are aggregated from a community of individuals, a collective representation of the connections and the strengths of the connections are visually expressed in a cloud of keywords or a tagcloud (Cress \& Held, 2013; Hearst \& Rosner, 2008). The attributes of the text used to represent features of the associated terms are usually text features (font weight, size and colour) and word placement (sorting, clustering and spatial layout) (Sinclair \& Cardew-Hall, 2008). The more frequently one particular tag has been used, the larger this particular tag appears in the tagcloud.

A tagcloud, similar in some respects to a table of contents or index, provides learners an overview and a general impression of content and supports tasks such as searching and browsing (Cress, Held, \& Kimmerle, 2013; Rivadeneira et al., 2007). The font size represents the frequency of underlying items, so as to provide an overall impression of the most prevalent or the unpopular topics. Xie and Lin (2016) recently reported a significant quantitative relationship between tagclouds and a team's collective cognition: tagclouds represented well team members' consensus about the relative importance of various concepts of a subject area. When properly used in a class, they could also provide a visual aid for students to re-examine their own understanding and knowledge. Novak and Gowin (1984) pointed out one usually needs time and mediating activities to digest novel and profound ideas. Tagclouds could potentially be effective for group discussions to facilitate students' 
understanding and conceptualisation of concepts as well as promote learning for all. However, research studies about the effect of tagclouds for group knowledge construction are extremely limited. This study aimed to fill this void. It examined the effect of tagclouds as anchors to guide small-group discussions as exhibited in participants’ concept maps.

\section{Research question}

This study examined the effect of tagcloud-anchored group discussions on participants' knowledge construction outcome. Specifically, the following research question guided this study: Was there any significant difference in the knowledge construction outcome exhibited in pre-service teachers' concept maps of those who participated in the tagcloud-anchored group discussions from those who did not participate in such discussions?

\section{Method}

\section{Participants and contexts}

The study took place at a medium-sized university in the northwestern United States. Study participants were 32 students enrolled in a general education course titled Families, Community, Culture. This course was an introductory course required for all pre-service teachers. All 32 participants were pre-education majors ranging in age from 22 to 35. Among them, 23 (72 \%) were female and nine (28\%) were male. Most of the participants (28, 88\%) were White, three (9\%) Hispanic, and one (3\%) Black.

\section{Procedure}

This study employed a posttest-only control-group experimental design. According to Creswell (2014), posttestonly control-group design can be more rigorous than the classical, traditional pretest-posttest control-group design within true experimental design methods. It is because the former 'controls for any confounding effects of a pretest, especially when the interval between a potential pretest and the posttest is within a shorter period of time (p.173). Participants were randomly assigned into six groups of five or six members in each group. This grouping was selected because Kameda, Stasson, Davis, Parks, and Zimmerman (1992) found that college students' motivation pattern in group work took an inverted U-shape for a group task, peaking at moderatesized subgrouping.

As part of the course requirements, all enrolled pre-service teachers were required to conduct a research project on parental involvement. The blogging and concept mapping activities were designed as pedagogical strategies to help facilitate the process. All participants in each group were required to participate in a team blogging activity using WordPress, an open-source blog software. To complete the blog activity, first, participants conducted literature research on parental involvement in school (related to student performance, factors, challenges and strategies) for five weeks and posted their findings each week on their respective team blog. They also attached at least five tags to each blog post. To make sure all participants were able to blog and tag, they watched a video created by one of the researchers about how to use the team blog site and how to attach tags to each blog post. In addition, the instructor of the course also dedicated half an hour's class time demonstrating the blog site to make sure that everyone was able to blog and tag. A tagcloud plug-in in all blog sites collected all tags and automatically generated a tagcloud for each team in real time based on the frequency of the tags attached to the team blogs by participants. However, tagclouds were only visible to researchers. Figure 1 is an example of a tagcloud generated from team blogs.

After the blogging-tagging task was completed, the researcher (other than the instructor) came to the class to recruit participants for the study (after being approved by the institution's Human Subject Committee). Three groups were randomly selected to participate in a group discussion with their respective blog group members where tagclouds served as anchors. No grade was assigned to participation in this study. In order to make sure that the participants were not sensitised by the outcome measure, a pretest was avoided to control for potential threats to internal validity caused by testing. Each group of participants gathered together around each table. 
Every participant then received his/her own group's tagcloud printed on a piece of paper and the other five groups' tagclouds printed on each piece of paper. The main task was for each participant to identify important concepts he/she missed or the whole group missed. Table 1 shows the guidelines for using tagclouds to guide the group discussion. The table also shows the cognitive process each step enabled according to the collaborative knowledge-building model Schellens and Valcke (2005) proposed. The discussions lasted between one and two hours.

\section{academic $_{\text {activities }}$ background barriers benefit ${ }_{\text {bilingual }}$ challenge collaboration community culture decision-making development diversity education environment ethnic Family family structure goal involvement language learning motivation needs opportunities parental involvement parent education parenting parents partner poverty programs relationships resources socialization socioeconomic strategy teachers theory two-way communication value volunteer Volunteering}

Figure 1. Example of a tagcloud generated by Group D (treatment group) in this study.

Table 1

Tagcloud-anchored group discussion guide

\section{Instruction for the group discussions}

Please work with your team members.

(1) Reflect on your blog and the tags you attached on your blog posts. Circle the ones you attached to your blog posts. (A copy of the team's tagcloud was handed out in paper format to each member of the team.)

(2) Work with your group; identify 10 tags that are smallest in the tag cloud. Write them down.

(3) If you are the author of the tag(s) identified in Step 2, please describe your blog post(s) where the tag was attached - tell your team why you think the tag is germane to parent involvement.

(4) If your group decides that the tag is not very relevant, then please cross it out in the list.

(5) The followings are the tag clouds generated by other groups in the same class. (The tagclouds of other teams were each printed on a separate piece of paper and handed out to the team members.) Work with your group, compare them with your own tagcloud, and circle 5-10 tags that your group missed but are important concepts related to parent involvement. Please make sure to reach group consensus before you start circling.

(6) For each of the tags identified in Step 5, also write down the reasons why your group thinks this tag is important. When you are done, please turn in your work to your instructor.

\section{Corresponding collaborative cognitive} process (Schellens \& Valcke, 2005)

Sharing and comparing

Identifying the most unpopular concepts (part of finding dissonance or inconsistency)

Asking and clarifying, restating and supporting (part of finding dissonance or inconsistency)

Negotiating, including proposing new co-constructions that encompass the negotiated resolution of the differences Sharing and comparing; identifying dissonance, inconsistency; negotiating

Creating statements of newly constructed knowledge 
In contrast, participants in control groups were required to revisit all blog sites (with the tagclouds hidden) and write a summary paper by comparing their own and others' blogs and tags. This assignment was to make sure all participants (in the non-discussion groups and the discussion groups) had similar opportunities to be exposed to various concepts and ideas posted by other members of the class and therefore reflect on the blogs and tags.

Before the end of the blogging activity, the instructor introduced to all students the types of concept maps and demonstrated how to construct a concept map in class. After the blogging and group discussion activities, all students independently completed their concept maps demonstrating their understanding of the research topic. Although concept maps were required for the course, the researchers only used those from participants who voluntarily participated in the study for data analysis. Figure 2 is an example of a concept map constructed by a participant.

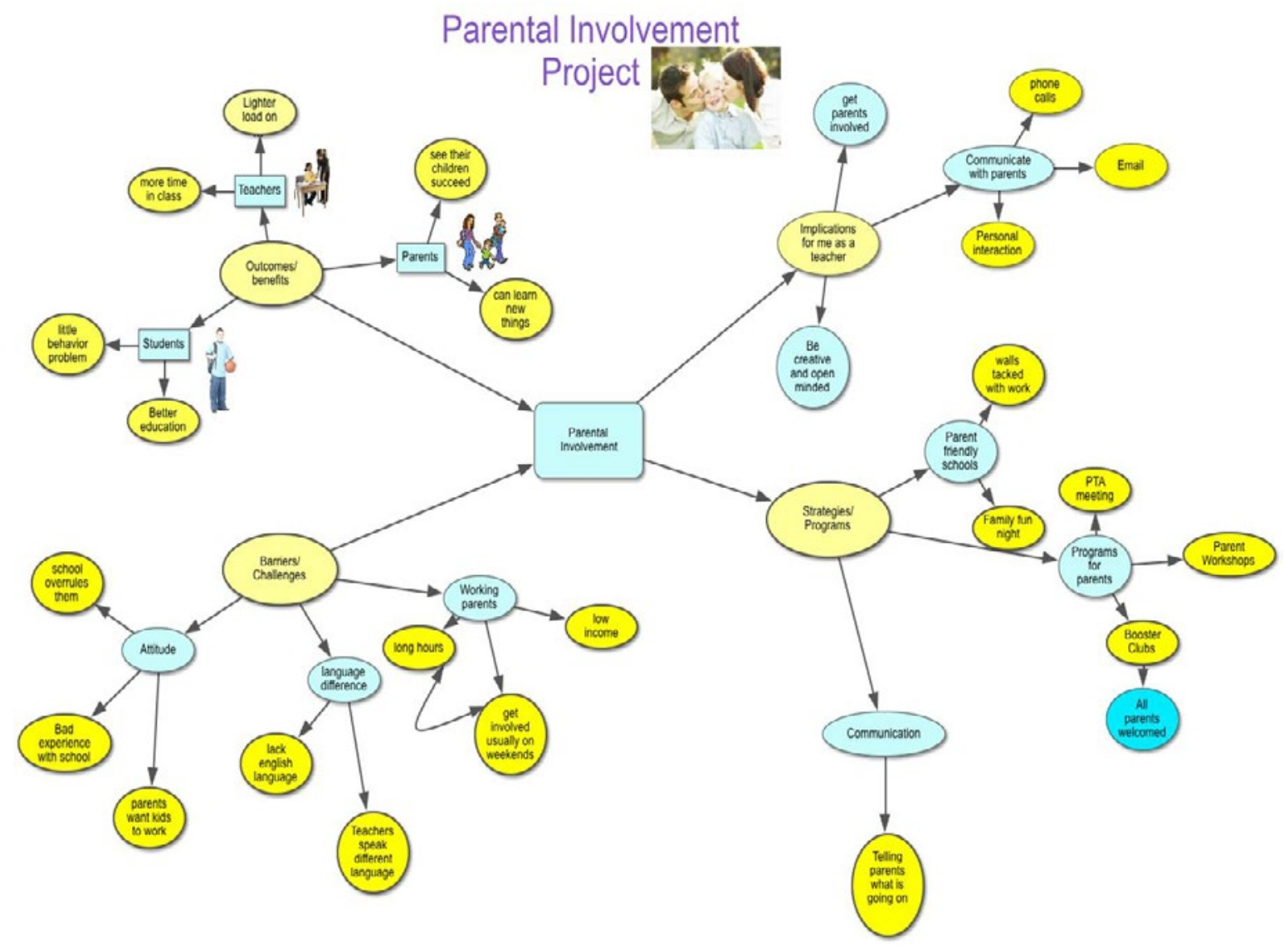

Figure 2. An example of a participant-constructed concept map.

\section{Instrumentation: Concept maps as an assessment tool}

According to Novak and Gowin (1984), concept maps are 'powerful evaluation tools' (p. 23) that provide a visual summary of what students have learned. Studies have shown that concept mapping is an appropriate assessment tool for testing students' academic achievement (e.g., McGaghie, McCrimmon, Thompson, Ravitch, \& Mitchell, 2000; West, Pomeroy, Park, Gerstenberger, \& Sandoval, 2000). There is a high correlation between concept mapping and other knowledge tests (Cañas, Bunch, Novak, \& Reiska, 2013). Previous studies (e.g., Kessler, Ditson, Anderson-Inman, \& Morris, 1996; Lin, Strickland, Ray, \& Denner, 2004) have shown that concept maps can be rated quantitatively and qualitatively and are reliable and valid instrument tools. 
Concept maps could be ideal tools to assess students' understanding and knowledge growth about a topic. When students construct their own concept maps using their own words to represent their ideas, new concepts are linked to students' existing cognitive structure (Reiska, Soika, Möllits, Rannikmäe, \& Soobard, 2015). Three aspects of a concept map - size, quality and structure - could be taken into consideration (Cañas et al., 2013; Novak \& Cañas, 2004). Size refers to the number of concepts, linking words or propositions; quality describes accuracy or relevance of concepts; and structure features how the ideas are connected with each other. For the purpose of this study, we only used the number and the quality of concepts to assess participants' knowledge on the research topic because we were most concerned with whether there was a difference in the amount and quality of concepts on the topic between the participants who took part in the tagcloud-anchored group discussions and those who did not. Cañas el al. (2010) pointed out that the structure measure could only provide 'limited information about the knowledge of students' (p. 76). As a result, the number of concepts in each participant's concept map was counted and the quality of concepts was evaluated based on the relevance of the concept to the research topic. A scoring rubric (see Table 2) was created based on Novak and Gowin's (1984) primary scoring scheme: A good concept map 'begins with broad, inclusive concepts and then leads to more specific, less inclusive concepts' (p. 97). Thus, concept maps were assessed on a 3-point scale (3 = superordinate: core concepts/more inclusive concepts, 2 = fundamental or major aspects of core concepts/less inclusive concepts and 1 = peripheral: elaborations and examples), as shown in Table 2 . The operationalisation of variables is further discussed in the following section.

Table 2

Concept quality scoring rubric in the concept map

\begin{tabular}{|c|c|c|c|}
\hline Category & Explanation & Examples & Score \\
\hline Superordinate & $\begin{array}{l}\text { The concepts in this category are core concepts, } \\
\text { which are central/main concepts and more } \\
\text { inclusive. }\end{array}$ & $\begin{array}{l}\text { Family engagement, } \\
\text { parental involvement }\end{array}$ & 3 \\
\hline Fundamental & $\begin{array}{l}\text { The concepts in this category constitute major } \\
\text { aspects related to the core concepts and are less } \\
\text { inclusive than the core concepts. }\end{array}$ & $\begin{array}{l}\text { Communication, strategy, } \\
\text { challenge/barrier }\end{array}$ & 2 \\
\hline Peripheral & $\begin{array}{l}\text { The concepts in this category are specific } \\
\text { concepts or examples related to the major } \\
\text { aspects of concepts. }\end{array}$ & $\begin{array}{l}\text { Parent-teaching meetings, } \\
\text { emails, letters sent to home }\end{array}$ & 1 \\
\hline
\end{tabular}

\section{Data collection and operationalisation of variables}

Data collection included participants' individual concept maps, all tags of each participant and group tagclouds from all six groups (three non-discussion and three tagcloud-anchored discussion groups). The study investigated the effect of tagcloud-anchored small-group discussions on participants' knowledge construction outcome as demonstrated in their final concept maps. All participants had amassed a number of concepts about the subject area during their five-week blogging and tagging activity before the tagcloud-anchored groups' discussions. The treatment groups then participated in face-to-face group discussions. Tagclouds generated by all groups were provided to guide their discussions on the research topic. Based on the tagclouds, participants were given an opportunity to compare and contrast the concepts generated by their own team and other teams and to negotiate the importance of various concepts. The tagcloud-anchored discussions aimed to broaden their learning by highlighting distinctive concepts in their own team's and other teams' tagclouds. To extend previous CSCL studies that examined the use of technology to support face-to-face group discussion (e.g., Chung et al., 2013), the study was conducted to find out if participation in the tagcloud-anchored discussions helped students incorporate more concepts at the end of the activity (as exhibited in their individual concept maps) that were different from what they had already acquired (as manifested in their own tags). To examine this, the concepts in each participant's concept map were first compared against the tags each participant had attached to his/her own blog posts. In this way, measure 1 - the percentage of a participant's ideas different from their own tags was generated: 


$$
\text { Measure } 1=\frac{\text { number of ideas different from the participant's own tags }}{\text { total number of ideas in a participant's concept map }}
$$

The hypothesis for measure 1 was the discussion groups (treatment) would incorporate a higher percentage of ideas different from their own tags than the non-discussion groups.

We further examined the concepts in the concept maps that were different from the participant's own tags in order to track down the sources of the knowledge elements participants acquired during the group discussions. To quantify the percentage of the concepts participants learned from their teams, the concepts from the participants' concept maps were compared with the tagcloud generated by their own team. Hence, measure 2 was the percentage of ideas different from the self-attached tags but within a participant's own team tagcloud:

$$
\text { Measure } 2=\frac{\begin{array}{c}
\text { number of ideas different from the participant's own tags } \\
\text { but within the team's tagcloud }
\end{array}}{\text { total number of ideas in a participant's concept map }}
$$

For measure 2, the hypothesis was that the discussion groups (treatment) would incorporate a higher percentage of ideas from their team's tagclouds than the non-discussion groups (control).

To examine whether the tagcloud-anchored group discussions on other teams' tagclouds had an impact on participants' knowledge contruction on the topic. Measure 3 was calculated. Measure 3 was the percentage of ideas that were outside of self-attached tags and outside of the participant's own team tagcloud.

$$
\text { Measure } 3=\frac{\begin{array}{c}
\text { number of ideas different from the participant's own tags } \\
\text { and outside of his or her team tagcloud }
\end{array}}{\text { total number of ideas in a participant's concept map }}
$$

The hypothesis for measure 3 was the tagcloud-anchored discussion groups would incorporate a higher percentage of ideas from outside of their team's tagclouds than the non-discussion groups.

In addition to the three measures parsing the effect of group discussions about different tagclouds on participants' knowledge construction outcome, a final step was taken to investigate if discussions about other teams' tagclouds by the treatment groups had an effect on the quality of the ideas in their concept maps especially those that were different from the self-attached tags and outside of the participant's own team tagcloud. The quality of the ideas was evaluated based on the relevance of each concept to the topic using a 3point scale as described above. The two researchers of this study evaluated ten of the total 32 concept maps and reached $100 \%$ agreement on the quality ratings. One researcher (also the instructor) then scored the rest and generated for each participant the total quality score of the concepts that were different from the self-attached tags and outside of the participant's team tagcloud. Since the number of such concepts could vary, the scores were converted (normalised) to fractional percentages by dividing the total score by the individual's total possible score. Thus, measure 4 was the normalised quality score.

$$
\begin{aligned}
& \text { Total quality score of ideas different from the self - attached tags } \\
& \text { Measure } 4=\frac{\text { and outside of his or her team's tagcloud }}{\text { total possible score of ideas different from the self -attached tags and }} \\
& \text { outside of his or her team tagcloud }
\end{aligned}
$$

The hypothesis for measure 4 was the tagcloud-anchored discussion groups would achieve a higher normalised quality score than the non-discussion groups. 


\section{Data analysis}

After all four measures as described in the previous section were generated for all participants, a one-way multivariate analysis of variance (MANOVA) was conducted to compare the tagcloud-anchored discussion and the non-discussion group participants.

\section{Results}

The study examined the effect of tagcloud-anchored group discussions on participants' knowledge construction outcome exhibited in their individual concept maps. Table 3 presents the MANOVA analysis results. Statistically significant differences were found for all four measures between the discussion and non-discussion groups.

Table 3

MANOVA analyses of all dependent measures

\begin{tabular}{|c|c|c|c|c|c|c|c|}
\hline Dependent variable & $\begin{array}{l}\text { Discussion } \\
\text { group }\end{array}$ & $d f$ & $\boldsymbol{F}$ & $M$ & $S D$ & $n$ & $p$ \\
\hline $\begin{array}{l}\text { Measure 1: Percentage of } \\
\text { concepts outside of the } \\
\text { participant’s tags }\end{array}$ & $\begin{array}{l}\text { No discussion } \\
\text { Discussion }\end{array}$ & 1 & 4.300 & $\begin{array}{l}.683 \\
.807\end{array}$ & $\begin{array}{l}.209 \\
.115\end{array}$ & $\begin{array}{l}16 \\
16\end{array}$ & $.047^{*}$ \\
\hline $\begin{array}{l}\text { Measure 2: Percentage of } \\
\text { concepts outside the participant's } \\
\text { tags but within the belonging } \\
\text { team's tagcloud }\end{array}$ & $\begin{array}{l}\text { No discussion } \\
\text { Discussion }\end{array}$ & 1 & 32.356 & $\begin{array}{l}.162 \\
.395\end{array}$ & $\begin{array}{l}.068 \\
.149\end{array}$ & $\begin{array}{l}16 \\
16\end{array}$ & $.000 * * *$ \\
\hline $\begin{array}{l}\text { Measure 3: Percentage of } \\
\text { concepts outside the participant's } \\
\text { tags and outside of the belonging } \\
\text { team's tagcloud }\end{array}$ & $\begin{array}{l}\text { No discussion } \\
\text { Discussion }\end{array}$ & 1 & 4.433 & $\begin{array}{l}.521 \\
.412\end{array}$ & $\begin{array}{l}.172 \\
.115\end{array}$ & $\begin{array}{l}16 \\
16\end{array}$ & $.044^{*}$ \\
\hline $\begin{array}{l}\text { Measure 4: Normalised quality } \\
\text { score of the concepts different } \\
\text { from the self-attached tags and } \\
\text { outside of the participant's team } \\
\text { tagcloud }\end{array}$ & $\begin{array}{l}\text { No discussion } \\
\text { Discussion }\end{array}$ & 1 & 18.333 & $\begin{array}{l}.671 \\
.919\end{array}$ & $\begin{array}{l}.210 \\
.098\end{array}$ & $\begin{array}{l}16 \\
16\end{array}$ & $.000 * * *$ \\
\hline
\end{tabular}

Participants from tagcloud-anchored discussion groups (measure 1: $M=80.7 \%, S D=.12$ ) incorporated a higher percentage of ideas in their final concept maps beyond their own learning (as exhibited by their blogs and tags) than those in non-discussion groups (measure $1: M=68.3 \%, S D=.21$ ). The difference was statistically significant, $F(1,31)=4.30, p<.05$. Among the ideas participants assimilated beyond their self-attached tags, a higher percentage of these ideas came from their own team's tagcloud for the discussion groups than the nondiscussion groups (measure $2: M=39.5 \%$ versus $M=16.2 \%, F(1,31)=32.35, p<.001$ ). The result of measure 3 also reveals statistically significant difference between the two groups, $F(1,31)=4.43, p<.05$. Yet, this result was contrary to our hypothesis. The discussion groups $(M=41.2 \%, S D=.17)$ incorporated a lower percentage of concepts outside the participant's tags and outside of their team's tagcloud as compared to the non-discussion groups $(M=52.1 \%, S D=.17)$. Further analysis indicates that for the concepts in measure 3 (outside the participant's tags and their team's tagcloud), the quality or relevancy of the concepts was higher for participants in the tagcloud-anchored discussion groups than for the non-discussion groups (measure 4: $M$ $=91.9 \%, S D=.098$ versus $M=67.1 \%, S D=.210, F(1,31)=18.33, p<.001)$. Overall, the results indicate the tagcloud-anchored group discussions had a positive impact on participants' knowledge construction outcome. 


\section{Discussion}

This study investigated the effect of using tagclouds as anchors on knowledge construction through small-group face-to-face discussions in a classroom environment. The study results indicate that participants in the tagcloudsupported discussion groups incorporated a higher percentage of ideas beyond their own learning than their counterparts in the non-discussion groups (see measure 1 : $M=80.7 \%$ versus $M=68.3 \%$ ). This result means that tagclouds allowed participants to collectively map out the level of pertinence of various tags or ideas in their team blogs. With the text features embedded, tagclouds provided an opportunity for participants to see popular/important and less important tags attached by team members. During the end-of-blog small-group discussions, with the tagclouds serving as anchors to their discussions, participants shared, compared, clarified and negotiated with group members the importance and reasons why they attached the tags. Consequently, participants in the discussion groups incorporated more ideas into their final learning as demonstrated in their concept maps, which they had not learned during their individual blogging activities, as compared to those in the non-discussion groups.

Another significant note from the study results is that tagclouds generated by their own groups had a positive influence on treatment-group participants' knowledge construction outcome as demonstrated in their concept maps. Among the ideas participants assimilated beyond their self-attached tags, a higher percentage of these ideas came from their own group's tagcloud for the treatment groups than the control groups (measure 2: $M=$ $39.5 \%$ versus $M=16.2 \%$ ). Since all participants contributed to the generation of the tagclouds, the discussions about the within-group tagclouds urged them to reflect on their learning, explain their reasoning, clarify their thinking and even defend their arguments to the rest of the group. Since tagclouds were collections of all tags attached by all participants, tagclouds as anchors for group discussions provided another opportunity for participants to expand their ideas or concepts that they had ignored before. Furthermore, tagclouds explicitly displayed the importance of the ideas or concepts recognised by the whole groups. Used as an anchor, a teamgenerated tagcloud provided a platform for students to reexamine their own understanding and knowledge related to the topic they studied. The group discussion activity of examining the tags, either the more relevant ones (large) or the less important ones (small), elevated their understanding of the content and facilitated the co-construction of content knowledge during discussions. These findings show that the tagcloud-supported group discussions also kept participants focused on ideas related to the learning task and extended their learning beyond what they had already knew.

Surprisingly, the study results show that participants in the discussion groups incorporated a lower percentage of ideas outside the participant's tags and outside of their team's tagcloud as compared to their counterparts in the non-discussion groups (measure $3: M=41.2 \%$ versus $M=52.1 \%$ ). A close analysis of the concept maps revealed that participants in the discussion groups accommodated more task-related concepts and produced higher-quality concept maps than the non-discussion groups (measure 4: normalised quality score $M=.919$ versus $M=.671$ ). A possible explanation is that the tagcloud-anchored discussions kept participants in the discussion groups focused on the concepts/tags within their team's tagcloud since most of the group discussions focused on the within-group tagcloud. The quality of concept maps demonstrated that tagclouds helped participants focus on concepts related to the topic they studied. Participants from the treatment groups not only assimilated more ideas from their own team tagclouds, they also accommodated quality ideas from other groups' tagclouds. In contrast, without being directed in their studying effort, the control groups incorporated a higher percentage of extraneous or less relevant concepts outside their tags and their team's tagcloud. Without discussions with group members, they may have difficulty distinguishing important concepts.

Because of the small group size, all participants in the tagcloud-anchored discussion groups had opportunities to engage in the discussion task. In line with Smith (1994), group discussion has a strong mediating effect on individual cognitive and conceptual processes. Overall, the study findings support the sociocultural framework and the model synthesised by Schellens and Valcke (2005) that co-construction of knowledge occurs through sharing, comparing, reasoning and negotiating in a social-constructivist learning environment in that the tagcloud-anchored discussions facilitated negotiation of ideas and promoted quality learning among group members. 


\section{Conclusion, limitations and future research}

This study demonstrated tagcloud-anchored discussions helped participants to compare their individual learning, explain their reasoning and develop new learning. The study findings suggest that appropriately designed technology could support group discussions within a constructivist model of knowledge building. This is achieved by providing guidelines to support individual participation and to ensure a willing exchange of viewpoints leading to consensus building in the group.

The current study showed that group discussions with learner-generated tagclouds could facilitate knowledge construction. The use of tagclouds as anchors for group discussions successfully guided and mediated the interactions among participants and supported meaningful and active participation for all participants. As a result, group discussions made participants' ideas more explicit and at the same time encouraged their reconceptions and re-building of the knowledge for the subject matter.

It is important to note the limitations of this study. The study is limited to teacher education and higher education. Therefore, some of the findings of this study may be unique to the particular circumstances and populations. It may not be directly applicable to other educational settings. The other limitation of this study is the use of concept maps as an assessment method. The evaluation of concept maps generally involves both content and structure of the map (McClure, Sonak, \& Suen, 1999). In this study, participants were asked to construct a concept map from scratch. Due to the lack of propositions, this study only examined the number and the quality of the ideas in participants' final concept maps. The structure of the concept maps was not analysed in this study. Future research could take the structure of concept maps into considerations.

Another worthy note that can be drawn from the study is the choice of technology and the use of technology in learning environments. Although technology can be effective for student learning, technology only presents a tool or facilitator for learning and knowledge construction (Edwards, 2002). Other studies of tagclouds focus on navigation and information-seeking on various websites. For example, Cress and Held (2013) investigated the use of tagclouds by users navigating the web. Word clouds, similar to tagclouds, have been introduced into various educational environments because the differentiated visual representations of terms are seen as an interesting and useful way to engage students in such activities as brainstorming, in-depth discussions, commenting and evaluating ideas and literature research (Baralt, Pennestri, \& Selvandin, 2011; deNoyelles \& Reyes-Foster, 2015; Krause et al., 2013; Wang, Elvemo, \& Gamnes, 2014). However, few studies have involved tagclouds as anchors for group discussions in face-to-face classroom environments. Using word clouds and tagclouds as anchors of group discussion could be quite different tasks for these pre-service teachers because the generation of word clouds is usually associated with web resources, whereas tagclouds are linked to ideas and descriptions provided by the pre-service teachers themselves. This study showed that when used as anchors to guide group discussions, although for a short period of time, tagclouds could very well promote learning. The researchers believe that the positive effect of this discussion mainly resulted from two facts: (1) the preservice teachers had already spent plenty of time investigating the topic during the blogging activity and therefore had established a fundamental knowledge network before the discussion; (2) since the tags were derived from their blog posts, the discussion guideline placed them into a self-defending and agreement-seeking position. The anchored discussion required them to constantly compare and contrast group knowledge with their own knowledge framework, which inevitably led to a broadened and deepened understanding of the topic. In practice, ample opportunities should be available for pre-service teachers to internalise the topic and become intrinsically motivated for a group discussion about a particular topic. The integration of technology, especially Web 2.0, becomes critical in preparing pre-service teachers' technological knowledge and skills to promote learning. This study may contribute to the field on the design of Web 2.0 to facilitate student learning and knowledge construction in higher education and teacher education. By exploring tagclouds as anchors for facilitating learning, this study may serve as an impetus for future investigations into the potential of tagclouds as learning or instructional tools in the classroom. Essentially, by exploring how tagclouds may support knowledge co-construction in groups, this study may offer insight into the role of tagclouds in learning and teaching. 


\section{References}

Baralt, M., Pennestri, S., \& Selvandin, M. (2011). Action research: Using wordles to teach foreign language writing. Language Learning \& Technology, 15(2), 12-22. Retrieved from http://llt.msu.edu/issues/june2011/actionresearch.pdf

Brookfield, S., \& Preskill, S. (2005). Discussion as a way of teaching: Tools and techniques for democratic classrooms. San Francisco, CA: Jossey-Bass.

Cañas, J. A., Bunch, L., Novak, J. D., \& Reiska, P. (2013). Cmapanalysis: An extensible concept map analysis tool. Journal for Educators, Teachers and Trainers, 4(1), 36-46. Retrieved from http://jett.labosfor.com/index.php/jett/article/view/46

Chung, C.-W., Lee, C.-C., \& Liu, C.-C. (2013). Investigating face-to-face peer interaction patterns in a collaborative web discovery task: The benefits of a shared display. Journal of Computer Assisted Learning, 29(2), 109-206. doi:10.1111/j.1365-2729.2012.00493.x

Cole, M. (1996). Cultural psychology: A once and future discipline. Cambridge, MA: Harvard.

Cress, U., \& Held, C. (2013). Harnessing collective knowledge inherent in tag clouds. Journal of Computer Assisted Learning, 29(3), 235-247. doi:10.1111/j.1365-2729.2012.00491.x

Cress, U., Held, C., \& Kimmerle, J. (2013). The collective knowledge of social tags: Direct and indirect influences on navigation, learning, and information processing. Computers \& Education, 60(1), 59-73. doi:10.1016/j.compedu.2012.06.015

Creswell, J. (2014). Research design: Qualitative, quantitative, and mixed methods approaches (4th ed.) Los Angeles, CA: Sage.

Dabbagh, N., \& Kitsantas, A. (2005). Using web-based pedagogical tools as scaffolds for self-regulated learning. Instructional Science, 33, 513-540. doi:10.1007/s11251-005-1278-3

deNoyelles, A., \& Reyes-Foster, B. (2015). Using word clouds in online discussions to support critical thinking and engagement. Online Learning, 19(4). Retrieved from ERIC database. (EJ1079614)

Edwards, C. (2002). Discourse on collaborative networked learning. Proceedings of Networked Learning Conference 2002 (pp. 85-92). Retrieved from http://www.networkedlearningconference.org.uk/past/nlc2002/proceedings/symp/05.htm - 05a

Gillies, R. M. (2011). Promoting thinking, problem-solving and reasoning during small group discussions. Teachers and Teaching, 17(1), 73-89. doi:10.1080/13540602.2011.538498

Hale, M., \& City, E. (2006). The teacher's guide to leading student-centered discussions: Talking about texts in the classroom. Thousand Oaks, CA: Corwin.

Hearst, M. A., \& Rosner, D. (2008). Tag clouds: Data analysis tool or social signaler? In Proceedings of the 41st Annual Hawaii International Conference on System Sciences, HICSS'08. New York, NY: IEEE. doi:10.1109/HICSS.2008.422

Kameda, T., Stasson, M., Davis, J., Parks, C., \& Zimmerman, S. (1992). Social dilemmas, subgroups, and motivation loss in task-oriented groups: In search of an "optimal” team size in division of work. Social Psychology Quarterly, 55(1), 47-56. Retrieved from http://www.jstor.org/stable/2786685

Kessler, R., Ditson, L.A., Anderson-Inman, L., \& Morris, J. D. (1996, April). Evaluating concept maps in traditional and electronic environment: Inter-rater reliability and beyond. Paper presented at the American Educational Research Association Conference, New York.

Krause, S. J., Baker, D., Carberry, A., Koretsky, M., Brooks, B. J., Gilbuena, D., ... Ankeny, C. J. (2013). Muddiest point formative feedback in core materials classes with YouTube, Blackboard, class warm-ups and word clouds. In Proceedings of the 2013 American Society for Engineering Education Annual Conference \& Exposition. Washington, DC: American Society for Engineering Education. Retrieved from https://www.asee.org/public/conferences/20/papers/7130/view

Lim, H. L. (2010). Scaffolding and knowledge appropriation in online collaborative group discussions. Contemporary Educational Technology, 1(4), 306-321. Retrieved from http://www.cedtech.net/articles/14/142.pdf

Lin, S.-Y., Strickland, J., Ray, B., \& Denner, P. (2004). Computer-based concept mapping as a prewriting strategy for middle school students. Meridian: A Middle School Computer Technologies Journal. Retrieved from https://www.ncsu.edu/meridian/sum2004/cbconceptmapping/cbconceptmapping.pdf 
Lowry, P. B., Roberts, T. L., Romano, N. C., Cheney, P. D., \& Hightower, R. T. (2006). The impact of group size and social presence on small-group communication: Does computer-mediated communication make a difference? Small Group Research, 37(6), 631-661. doi:10.1177/1046496406294322

McClure, J. R., Sonak, B., \& Suen, H. K. (1999). Concept map assessment of classroom learning: Reliability, validity, and logistical practicality. Journal of Research in Science Teaching, 36(4), 475-492. doi:10.1002/(SICI)1098-2736(199904)36:4<475::AID-TEA5>3.0.CO;2-O

McGaghie, W. C., McCrimmon, D. R., Thompson, J. A., Ravitch, M. M., \& Mitchell, G. (2000). Medical and veterinary students' structural knowledge of pulmonary physiology concepts. Academic Medicine, 75(4), 362-368. Retrieved from http://journals.lww.com/academicmedicine/toc/2000/04000

Meloth, M. C., \& Deering, P. D. (1999). The role of the teacher in promoting cognitive processing during collaborative learning. In A. M. O’Donnell \& A. King (Eds.), Cognitive perspectives on peer learning (pp. 235-255). Mahwah, NJ: Erlbaum.

Ng, C. S. L., Cheung, W. S., \& Hew, K. F. (2010). Solving ill-structured problems in asynchronous online discussions: Built-in scaffolds vs. no scaffolds. Interactive Learning Environments, 18(2), 115-134. doi:10.1080/10494820802337629

Novak, J. D., \& Cañas, A. J. (2004). Building on constructivist ideas and CmapTools to create a new model for education. In A. J. Cañas, J. D. Novak, \& F. M. González (Eds.), Concept maps: Theory, methodology, technology. Proceedings of the 1st International Conference on Concept Mapping. Pamplona, Spain: Universidad Pública de Navarra. Retrieved from http://cmc.ihmc.us/cmc/CMCProceedings.html

Novak, J. D., \& Gowin, D. B. (1984). Learning how to learn. New York, NY: Cambridge University Press.

Nussbaum, M., Alvarez, C., McFarlane, A., Gomez, F., Claro, S., Radovic, D. (2009). Technology as small group face-to-face collaborative scaffolding. Computers \& Education, 52(1), 147-153. doi:10.1016/j.compedu.2008.07.005

Pea, R. D. (1993). Practices of distributed intelligence and designs for education. In G. Salomon (ed.), Distributed cognitions (pp. 47-87). Cambridge, MA: University Press.

Rabow, J., Charness, M. A., Kipperman, J., \& Radcliffe-Vasile. S. (1994). William Fawcett Hill's learning through discussion (3rd ed.). Thousand Oaks, CA: Sage.

Reiser, R. A., \& Dempsey, J. V. (2012). Trends and issues in instructional design and technology (3rd. ed.). Boston, MA: Pearson.

Reiska, P., Soika, K., Möllits, A., Rannikmäe, M., \& Soobard, R. (2015). Using concept mapping method for assessing students’ scientific literacy. Procedia: Social and Behavioral Sciences, 177, 352-357. doi:10.1016/j.sbspro.2015.02.357

Rivadeneira, A. W., Gruen, D. M., Muller, M. J., \& Millen, D. R. (2007). Getting our head in the clouds: Toward evaluation studies of tagclouds. In Proceedings of the SIGCHI Conference on Human Factors in Computing Systems. 995-998. doi:10.1145/1240624.1240775

Schellens, T., \& Valcke, M. (2005). Collaborative learning in asynchronous discussion groups: What about the impact on cognitive processing? Computers in Human Behavior, 21(6), 957-975. doi:10.1016/j.chb.2004.02.025

Sinclair, J., \& Cardew-Hall, M. (2008). The folksonomy tag cloud: When is it useful? Journal of Information Science, 34(1), 15-29. doi:10.1177/0165551506078083

Smith, J. B. (1994). Collective intelligence in computer-based collaboration. Hillsdale, NJ: Lawrence Erlbaum Associates.

Trant, J. (2009). Studying social tagging and folksonomy: A review and framework. Journal of Digital Information, 10(1), 1-44. Retrieved from https://journals.tdl.org/jodi/index.php/jodi/article/view/269/278

Vygotsky, L. (1962). Thought and language. Cambridge, MA: MIT Press.

Wang, A. I., Elvemo, A. A., \& Gamnes, V. (2014). Three social classroom applications to improve student attitudes. Education Research International. doi:10.1155/2014/259128

West, D., Pomeroy, J. R., Park, J., Gerstenberger, E., \& Sandoval, J. (2000). Critical thinking in graduate medical education. Journal of the American Medical Association, 284(9), 1105-1110. doi:10.1001/jama.284.9.1105

Xie, Y., \& Lin, S.-Y. (2016). Tagclouds and group cognition: Effect of tagging support on students' reflective learning in team blogs. British Journal of Educational Technology, 47(6), 1135-1150. doi:10.1111/bjet.12293 
Yeh, S.-W., Lo, J.-J., Huang, J.-J. (2011). Scaffolding collaborative technical writing with procedure facilitation and synchronous discussion. Computer-Supported Collaborative Learning, 6, 397-419. $\underline{\text { doi:10.1007/s11412-011-9117-9 }}$

Corresponding author: Shu-Yuan Lin, linshu@isu.edu

Australasian Journal of Educational Technology @ 2017.

Please cite as: Lin, S.-Y., \& Xie, Y. (2017). Effects of tagcloud-anchored group discussions on pre-service teachers' collaborative knowledge construction. Australasian Journal of Educational Technology, 33(2), 73-85. https://doi.org/10.14742/ajet.2885 